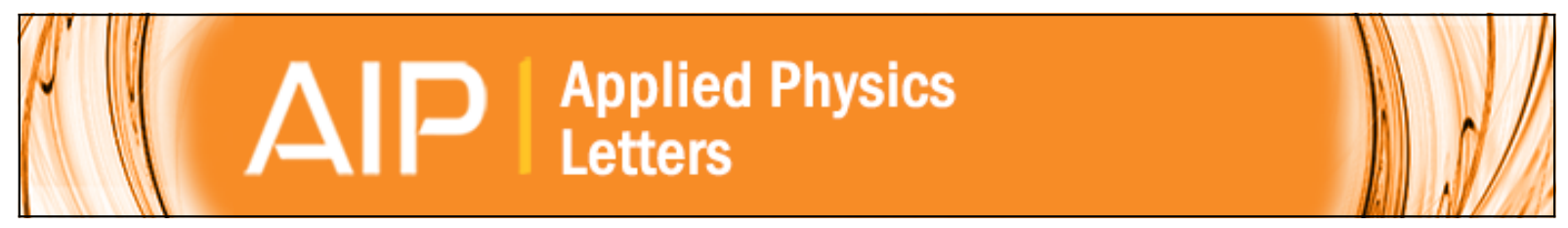

Nonlinear optical absorption of antimony and lead oxyhalide glasses

Renato E. de Araujo, Cid B. de Araújo, Gäel Poirier, Marcel Poulain, and Younes Messaddeq

Citation: Applied Physics Letters 81, 4694 (2002); doi: 10.1063/1.1529310

View online: http://dx.doi.org/10.1063/1.1529310

View Table of Contents: http://scitation.aip.org/content/aip/journal/apl/81/25?ver=pdfcov

Published by the AIP Publishing 


\title{
Nonlinear optical absorption of antimony and lead oxyhalide glasses
}

\author{
Renato E. de Araujo and Cid B. de Araújo a) \\ Departamento de Física, Universidade Federal de Pernambuco, 50670-901 Recife, PE, Brazil \\ Gäel Poirier and Marcel Poulain \\ Laboratoire des Matériaux Photoniques, Université de Rennes I, Campus de Beaulieu, Rennes, France \\ Younes Messaddeq \\ Instituto de Química, Universidade do Estado de São Paulo, 14801-970 Araraquara, SP, Brazil
}

(Received 2 August 2002; accepted 22 October 2002)

\begin{abstract}
Nonlinear optical properties and optical limiting behavior of antimony and lead oxyhalide glasses were studied using laser pulses of $80 \mathrm{ps}$ at $532 \mathrm{~nm}$. The standard $Z$-scan technique was used to determine large nonlinear absorption coefficients which range from 11 to $20 \mathrm{~cm} / \mathrm{GW}$, using intensities of $100 \mathrm{MW} / \mathrm{cm}^{2}$. Photodarkening was observed when intensities larger than $\approx 200$ MW/ $/ \mathrm{cm}^{2}$ were incident on the samples. (C) 2002 American Institute of Physics.
\end{abstract}

[DOI: $10.1063 / 1.1529310]$

Antimony and lead oxyhalide glasses were presented first in Ref. 1, which reports some of their optical properties. Further studies confirmed the high refractive index and the large infrared transmission window of these glasses, which are comparable to the characteristics of fluoride glasses., ${ }^{2,3}$ Antimony oxide, $\mathrm{Sb}_{2} \mathrm{O}_{3}$, is the main glass component and is considered as the glass former. Glass transition temperature is $\approx 300^{\circ} \mathrm{C}$ and the mean value of the refractive index is 2.1 . The thermal stability of these glasses is larger than the stability of fluorozirconate glass (ZBLAN), from which optical fibers have been drawn. They present characteristics similar to telluride glasses, without the specific problems related to tellurium toxicity. Most of the work done on $\mathrm{Sb}_{2} \mathrm{O}_{3}$-based glasses was centered upon glass formation and general physical properties, particularly thermal characteristics. Recently, new methods of preparation have been developed, and presently samples of improved optical quality can be obtained. ${ }^{4,5}$ Optical experiments reported so far were performed at low intensity levels. The possibility of large nonlinear response of antimony and lead oxyhalide glasses has been recognized recently. ${ }^{4}$

In this work, we report on nonlinear optical experiments performed with glass samples with the following compositions: $65 \mathrm{Sb}_{2} \mathrm{O}_{3}-22 \mathrm{PbBr}_{2}-5 \mathrm{PbI}_{2}-5 \mathrm{~B}_{2} \mathrm{O}_{3}-3 \mathrm{KCl}$ (sample A); $\quad 90 \mathrm{Sb}_{2} \mathrm{O}_{3}-10 \mathrm{PbI}_{2} \quad$ (sample $\mathrm{B}$ ); and $80 \mathrm{Sb}_{2} \mathrm{O}_{3}-10 \mathrm{PbBr}_{2}-10 \mathrm{PbCl}_{2}$ (sample C). Starting materials are $\mathrm{Sb}_{2} \mathrm{O}_{3}$ (purity larger than $99 \%$ ); $\mathrm{PbCl}_{2}$ (purity of 99\%); $\mathrm{PbBr}_{2}$ (purity larger than 99\%); $\mathrm{PbI}_{2}$ (purity of $98.5 \%$ ); $\mathrm{B}_{2} \mathrm{O}_{3}$ (purity of 99.6\%), and $\mathrm{KCl}$ (purity of 99.9\%). Powders are mixed and put in silica tubes of about $10 \mathrm{~mm}$ diameter or in a covered crucible. Temperature is raised rapidly to $850-900{ }^{\circ} \mathrm{C}$. A homogeneous melt is usually obtained after 5 to $10 \mathrm{~min}$. Melting time should not be too long to avoid loss of volatile halides that could escape from the melt. When a clear liquid is obtained, it is cast into a brass mold heated at $150{ }^{\circ} \mathrm{C}$ to prevent thermal shock on cooling. Fi-

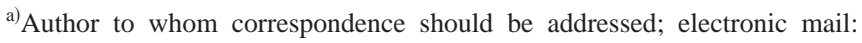
cid@df.ufpe.br
}

nally, samples are annealed for a few hours at a temperature lower than the glass transition temperature. The samples appear yellow in transmission. Scattering defects limit the optical quality of large samples. The samples used have dimensions of $5 \mathrm{~mm} \times 3 \mathrm{~mm} \times 0.4 \mathrm{~mm}$.

Figure 1 shows the optical absorption spectra of the three samples studied. The samples present a high transparency window for wavelengths larger than $\approx 500 \mathrm{~nm}$ and a strong absorption in the blue region. All experiments were made at room temperature. The visible and the infrared transmission of related glasses compositions reported in Ref. 4 are similar to the results observed in the present work.

To characterize the nonlinear optical behavior of the samples, the second harmonic beam of a cw pumped, $Q$-switched, and mode-locked Nd:YAG laser $(532 \mathrm{~nm}$, pulses of $80 \mathrm{ps}$ ) was used. A single pulse at $10 \mathrm{~Hz}$ was selected by a pulse picker. The low repetition rate was used to avoid the influence of cumulative effects. The linearly polarized light beam was focused by a $15 \mathrm{~cm}$ focal-distance

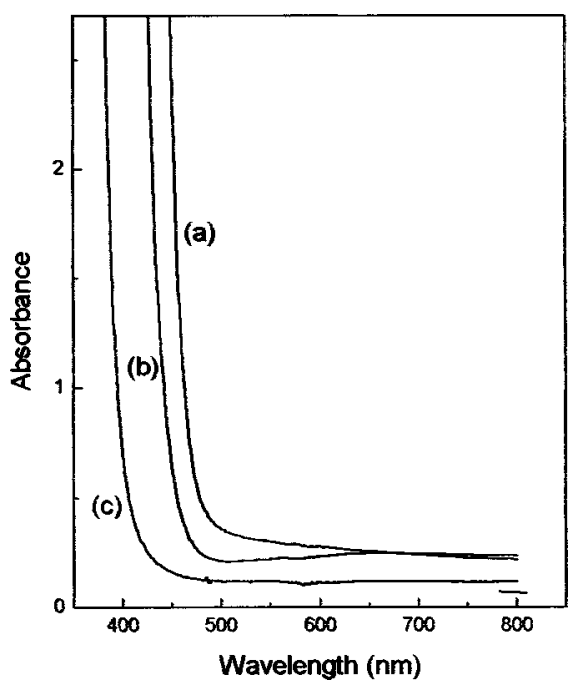

FIG. 1. Optical absorption spectra of the studied samples: (a) sample A, (b) sample B, and (c) sample C. Sample thickness: $0.4 \mathrm{~mm}$. 


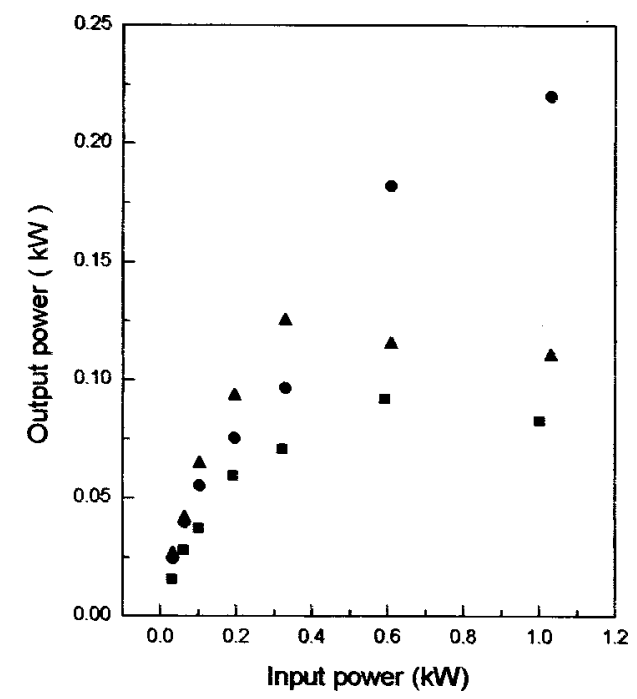

FIG. 2. Plot of the transmitted power as a function of the incident laser power: $(\boldsymbol{\square})$ sample A, $(\boldsymbol{\Lambda})$ sample B, and $(\bullet)$ sample C.

lens. The light transmitted through the sample was detected by a photomultiplier coupled to boxcar and computer.

When light passes through the samples its amplitude is attenuated by surface reflections, absorption, and scattering. In the present case the losses are primarily due to reflection and absorption because homogeneous regions of the samples were carefully selected to perform the measurements. Cumulative changes in transmission due to trapping of electrons could affect the results, but their contribution is not expected to be relevant in the experiments performed with low peak powers at low repetition rate.

Figure 2 shows the behavior of the transmitted light as a function of the incident laser peak power. Notice that the measurements have shown a decrease in the transmittance when the incident light intensity increases. This is an indication of nonlinear absorption due to multiphoton absorption or reverse saturable absorption. ${ }^{6}$ When the laser intensity is increased beyond $\approx 200 \mathrm{MW} / \mathrm{cm}^{2}$, a photodarkening effect is observed with dark spots clearly seen using an optical microscope. The intensity of the transmitted beam shows a decrease in a time scale of $10-50 \mathrm{~s}$ for pumping intensities of $\approx 200 \mathrm{MW} / \mathrm{cm}^{2}$ and larger, which corroborates the presence of photodarkening.

Nonlinear absorption and nonlinear refraction were investigated using the $Z$-scan technique, ${ }^{7}$ which allows measurement of the sign and the absolute value of the nonlinear refractive index $n_{\mathrm{NL}}$, and the nonlinear absorption coefficient $\alpha_{\mathrm{NL}}$. The method exploits the light-matter interaction, so that a single incident beam induces a self-phase distortion propagating inside the sample, and originates an amplitude distortion of the beam wave front as measured after it leaves the sample. To determine $n_{\mathrm{NL}}$ and $\alpha_{\mathrm{NL}}$, the sample is moved along the beam propagation direction (direction $Z$ ) using a computer controlled delay line. Negative values of $Z$ correspond to locations of the sample between the focusing lens and its focal plane. Measuring the variation of the transmitted beam intensity through a circular aperture placed in front of a detector in the far-field region (closed-aperture $Z$-scan), it is possible to determine the sign and the magnitude of $n_{\mathrm{NL}}$. When all of the light beam passing through the sample
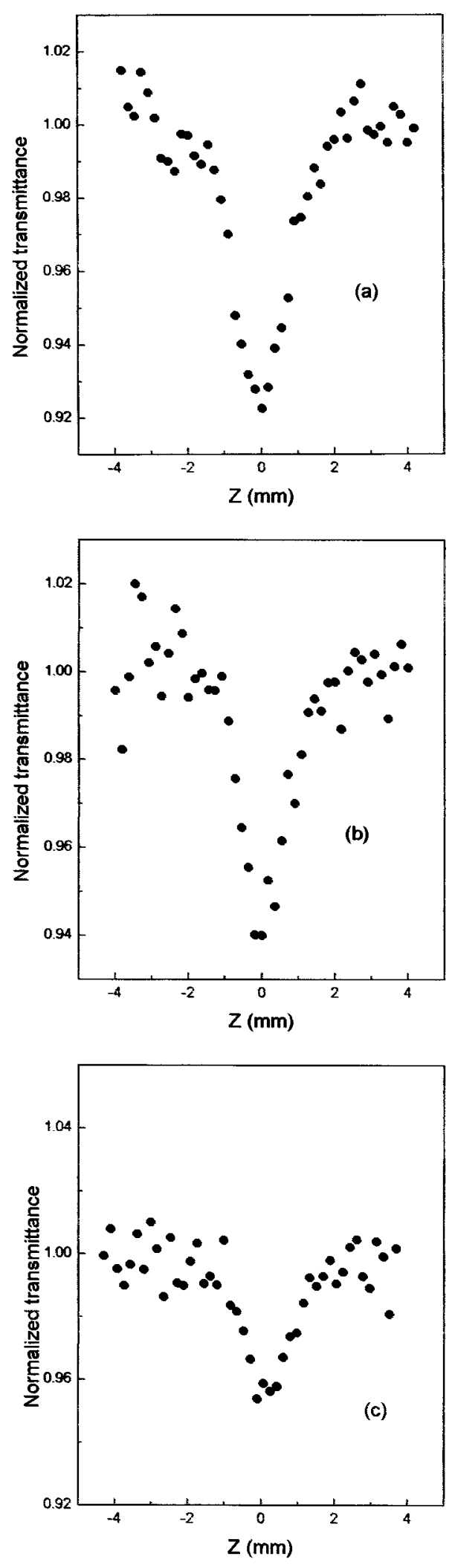

FIG. 3. Open-aperture $Z$-scan results. (a) sample A, (b) sample B, and (c) sample C. Laser intensity: $100 \mathrm{MW} / \mathrm{cm}^{2}$.

is detected as a function of $Z$ (open-aperture $Z$-scan), it is possible to determine $\alpha_{\mathrm{NL}}$.

Open-aperture $Z$-scan measurements were performed at $100 \mathrm{MW} / \mathrm{cm}^{2}$, such that photodarkening is not observed. Figure 3 shows the results for the samples studied in which the dip observed is due to nonlinear absorption. For the analysis of the data, we considered that the light attenuation 
through the sample is described by $d I / d z=-\left(\alpha_{L}+\alpha_{\mathrm{NL}} I\right) I$, where $I$ is the light intensity along the propagation direction, $\alpha_{L}\left(\alpha_{\mathrm{NL}}\right)$ is the linear (nonlinear) absorption coefficient. The values of $\alpha_{L}$ were obtained from the absorption spectra. Numerical integration gives the transmitted intensity $T$, just after the beam exits the sample. ${ }^{6,7}$ By comparing the expression for $T$ with the experimental measurements the following nonlinear absorption coefficients were determined: 20 $\mathrm{cm} / \mathrm{GW}$ (sample A); $16 \mathrm{~cm} / \mathrm{GW}$ (sample B), and $11 \mathrm{~cm} / \mathrm{GW}$ (sample C). The lowering of $\alpha_{\mathrm{NL}}$ from sample $\mathrm{A}$ to $\mathrm{C}$ is expected due to the increasing of the laser frequency detuning from the energy band gap as one goes from sample A to C. The large values of $\alpha_{\mathrm{NL}}$ suggest that these glass compositions may be competitive with known materials, ${ }^{8-15}$ for applications such as optical limiting at $532 \mathrm{~nm}$. The closedaperture $Z$-scan measurements, performed at $100 \mathrm{MW} / \mathrm{cm}^{2}$, did not show nonlinear refractive behavior, indicating that the value of $n_{\mathrm{NL}}$ is below our detection limit, which corresponds to changes in the refractive index of $\sim 10^{-5}$.

As can be seen in Fig. 1, the optical frequency used in this work is approaching the single-photon transition frequency, and this explains the large nonlinear absorption coefficient measured. Thus, it is possible that a contribution for the nonlinear absorption originates from photo-excited freecarriers. Pump-and-probe experiments using shorter laser pulses will be performed in the future to clarify this point.

In conclusion, we note that the present results represent a nonlinear optical study of antimony and lead oxyhalide glasses. The measurements show that, due to the large nonlinear absorption coefficients measured, these glass compositions may be useful for optical limiting applications. The occurrence of photodarkening in the samples suggests that they can also be useful for inscribing Bragg gratings using green lasers of moderate power.
Financial support for this work by the Brazilian Conselho Nacional de Desenvolvimento Científico e Tecnológico (CNPq), Programa de Nucleos de Excelência-PRONEX (Brazil) and Conseil Régional de Bretagne (France) are gratefully acknowledged. A. S. L. Gomes is acknowledged for sharing the laser and other equipment used in the experiments. We are grateful to M. T. Carvalho for helping in the early stage of the experiments.

${ }^{1}$ B. Dubois, H. Aomi, J. J. Videau, J. Portier, and P. Haggenmuller, Mater. Res. Bull. 19, 1317 (1984).

${ }^{2}$ B. Dubois, J. J. Videau, M. Couzi, and J. Portier, J. Non-Cryst. Solids 88, 355 (1986).

${ }^{3}$ M. M. Ahmed and D. Holland, Glass Technol. 28, 141 (1987)

${ }^{4}$ G. Poirier, M. Poulain, and M. Poulain, J. Non-Cryst. Solids 284, 117 (2001)

${ }^{5}$ M. Nalin, M. Poulain, M. Poulain, S. J. L. Ribeiro, and Y. Messaddeq, J. Non-Cryst. Solids 284, 110 (2001).

${ }^{6}$ L. W. Tutt and T. F. Boggess, Prog. Quantum Electron. 17, 299 (1993).

${ }^{7}$ M. Sheik-Bahae, A. A. Said, T. H. Wei, D. J. Hagan, and E. W. Van Stryland, IEEE J. Quantum Electron. 26, 760 (1990).

${ }^{8}$ R. A. Negres, J. M. Hales, A. Kobyakov, D. J. Hagan, and E. W. Van Stryland, Opt. Lett. 27, 270 (2002), and references therein.

${ }^{9}$ M. Sheik-Bahae, D. J. Hagan, and E. W. Van Stryland, Phys. Rev. Lett. 65, 96 (1990).

${ }^{10}$ G. S. Maciel, N. Rakov, C. B. de Araújo, A. A. Lipovskii, and D. K. Tagantsev, Appl. Phys. Lett. 79, 584 (2001).

${ }^{11}$ G. S. Maciel, C. B. de Araújo, A. A. Lipovskii, and D. K. Tagantsev, Opt. Commun. 203, 441 (2002).

${ }^{12}$ G. Poirier, C. B. de Araújo, Y. Messaddeq, S. J. L. Ribeiro, and M. Poulain, J. Appl. Phys. 91, 10221 (2002).

${ }^{13}$ J. S. Shirk, Opt. Photonics News 11, 19 (2000).

${ }^{14}$ J. D. Bhawalkar, G. S. He, and P. N. Prasad, Rep. Prog. Phys. 59, 1041 (1996).

${ }^{15}$ G. S. He, T. C. Lin, P. N. Prasad, R. Kannan, R. A. Vaia, and L. S. Tan, Opt. Express 10, 566 (2002), and references therein. 